\title{
Fracture toughness of L-PBF fabricated aluminium-silicon: a quantitative study on the role of crack growth direction with respect to layering
}

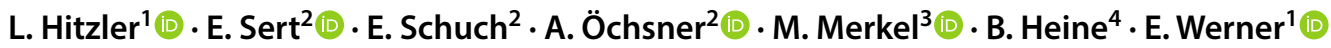

Received: 6 September 2019 / Accepted: 21 January 2020 / Published online: 7 February 2020

(c) The Author(s) 2020

\begin{abstract}
Laser powder bed fusion has become one of the major techniques within metal additive manufacturing, especially when delicate structures and high geometric accuracy are concerned. Lately, the awareness of the material-specific macroscopic anisotropy has risen and led to widespread investigations on the static mechanical strength. However, little is known about the fracture behavior of the layer-wise fabricated metal components and their affinity of crack propagation between consecutive layers, which is particularly important for aluminium-silicon alloys containing embrittled zones in double-irradiated areas. A recent study indicated that there is a significant drop in fracture toughness in case the crack growth direction is parallel to the layering. To investigate this matter further and to shed light on the fracture toughness behavior in the range of a $0^{\circ}-45^{\circ}$ angle offset between the crack growth direction relative to the layering, notched samples with varying polar angles were subjected to mode I fracture toughness testing. Our results indicate that the fracture toughness is an almoststable characteristic up to a mismatch of about $20^{\circ}$ between the crack propagation path and the layering, at which point the fracture toughness decreases by up to $10 \%$.
\end{abstract}

Keywords Additive manufacturing $\cdot$ Selective laser melting $\cdot$ Tensile load $\cdot$ Notched specimen $\cdot$ Inclination $\cdot$ AlSi10Mg

\section{Introduction}

Additive manufacturing (AM) methods, such as laser powder bed fusion (L-PBF), are outstanding freeform fabrication techniques, capable of fabricating directly deployable components without the necessity of special tooling, and are extremely efficient when only small quantities are required [1-3]. The complete melting of the raw material enables the generation of fully dense parts within a single production step and - due to the rapid cooling rates—exhibit an almost

L. Hitzler

hitzler@wkm.mw.tum.de

1 Institute of Materials Science and Mechanics of Materials, Technical University Munich, 85748 Garching, Germany

2 Faculty of Mechanical Engineering, Esslingen University of Applied Sciences, 73728 Esslingen, Germany

3 Institute for Virtual Product Development, Aalen University of Applied Sciences, 73430 Aalen, Germany

4 Faculty of Mechanical Engineering, Aalen University of Applied Sciences, 73430 Aalen, Germany instantaneous solidification, thereby achieving an ultra-finegrained microstructure, which often exceeds the specifications of the respective conventional material.

On the downside, the systematic material development and prediction of material properties are by no means trivial. The material characteristics are known to be potentially anisotropic, whereby the magnitude of anisotropy depends on the fabrication settings, such as the irradiation parameters and the scan strategy, as well as the chosen raw material $[4,5]$. Moreover, some materials, especially precipitationhardenable ones, additionally may also be inhomogeneous. For aluminium-silicon (AlSi) alloys, inhomogeneities are twofold. On the macroscale, varying age-hardening states may occur for AlSiMg alloys in all cases where the preheating temperature employed during fabrication is within the artificial ageing regime. If present, samples or components in their as-fabricated state exhibit a height- and built-timedependent fluctuation in strength and hardness $[6,7]$. On the microscale, the rapid cooling results in an increased (nonequilibrium) solubility of silicon in the $\alpha-\mathrm{Al}$ crystal structure and favours the formation of distinct $\mathrm{Si}$-segregations along grain boundaries and predominantly along scan track 
boundaries [8-11]. These Si-enriched areas are rather brittle and often appear as predetermined locations for failure. A previous study on the fracture toughness of AlSi $10 \mathrm{Mg}$ suggested that agglomerated embrittlements between consecutive layers lowered the fracture toughness by about $20 \%$ [12]. This effect was noted in samples where the crack propagation was in line with the layering, which resulted in fracture toughness values that were inferior to all other configurations tested. In addition, the built height and the corresponding age-hardening state was found to have only a minor impact, and are, thus, pointing to the $\mathrm{Si}$-segregations as major cause for fluctuations in the fracture toughness. This early investigation was limited to three distinct polar angles of investigated samples, i.e., $0^{\circ}, 45^{\circ}$, and $90^{\circ}$, and clearly demonstrated that the area of interest lays for polar angles between $45^{\circ}$ and $90^{\circ}$, synonymous for the $0^{\circ}-45^{\circ}$ offset regime of layering to crack growth direction (Fig. 1).

Within this study, the fracture toughness in the aforementioned crucial range was investigated on notched AlSi10Mg tensile testing specimens. Samples were tested in their machined condition, without the consideration of a post-heat treatment, like solution annealing or artificial age hardening.

\section{Methodology}

\subsection{Fabrication}

Flat tensile specimen type E $5 \times 10 \times 40$, according to the German standard DIN 50125:2016, were fabricated with a common AlSi10Mg powder (average particle size of $37 \mu \mathrm{m}$ ) on an SLM 280 HL machine (SLM Solutions AG, Lübeck, Germany), equipped with a $400 \mathrm{~W}$ Yb fibre laser. The preheating temperature was set to $200{ }^{\circ} \mathrm{C}$. A detailed listing of the utilized irradiation parameters is provided in the section "Appendix". Samples were built with an oversize of

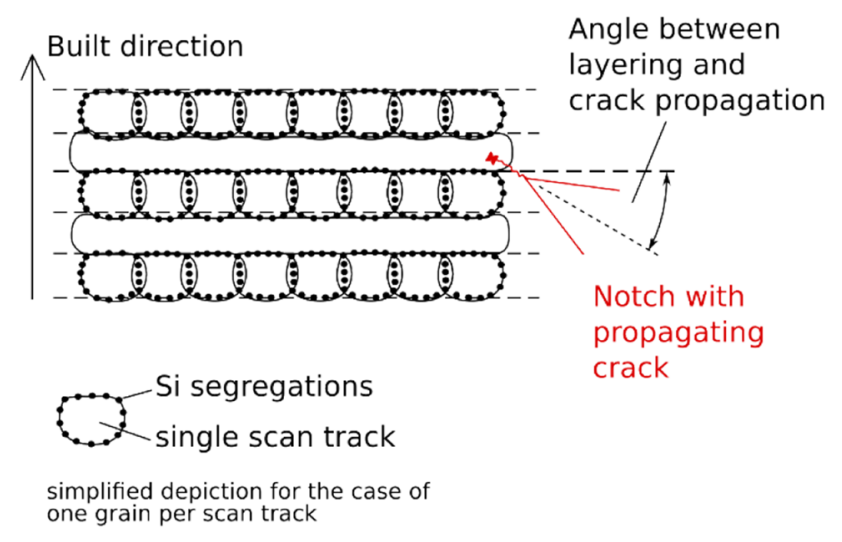

Fig. 1 Schematic of the layered LPBF microstructure in $\mathrm{Al}-\mathrm{Si}-\mathrm{Mg}$ with localized Si-segregations, including the crack growth to layer angle, adapted from [4] roughly $1 \mathrm{~mm}$ and milled to their final shape, with the addition of holes with a diameter of $7.5 \mathrm{~mm}$ drilled in the clamping areas for a distortion-free clamping of the specimens. Notches were introduced with a thin and sharp disc-milling cutter with a thickness of $1 \mathrm{~mm}$ and a $45^{\circ}$ tip angle. For the current quantitative investigation on the polar angle influence, pre-cycling for crack initiation was neglected. Specimens were fabricated in five distinct polar angles $\Phi$, namely, $45^{\circ}, 50^{\circ}, 70^{\circ}, 80^{\circ}$, and $90^{\circ}$ (Fig. 2). For clarity, it is noted that a polar angle of $90^{\circ}$ represents a sample whose longitudinal axis is perpendicular to the layering.

\subsection{Testing procedure}

The fracture toughness tests were performed on an MTS Landmark testing machine (MTS Systems, Minnesota USA) with a maximum load of $100 \mathrm{kN}$, equipped with a force transducer load cell (model 661.20F-03). The crack-mouth opening was recorded with a double cantilever clip-in displacement gauge (MTS model 632.03F-30), based on the ASTM 399-08 standard, which locked in place by pre-tension and obtained the crack opening reading on the retaining grooves (Fig. 3). The test itself was carried out very similar to a tensile test, with the cross-head speed set to a constant $0.2 \mathrm{~mm} / \mathrm{min}$ until failure occurred.

\subsection{Evaluation scheme}

The experimental data of the fracture toughness tests were evaluated in accordance to the ASTM E 1820-09, following the explanations on the precise procedure outlined in [13]. First, the force-crack mouth opening curves were compared with idealised ones representing characteristic

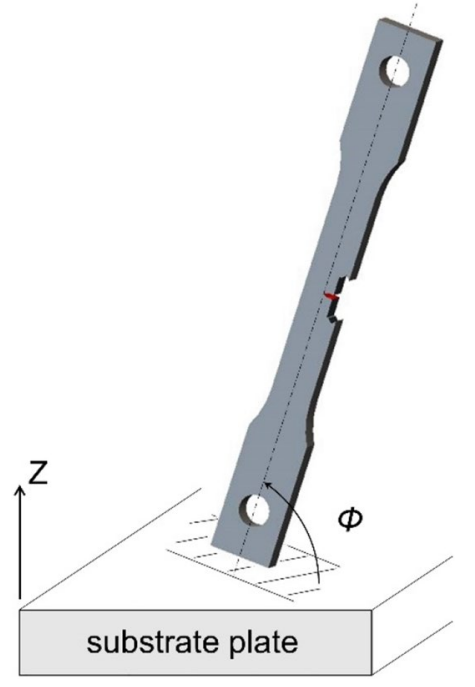

Fig. 2 Nomenclature for the inclination of specimens as a function of the polar angle $\Phi$ 
Fig. 3 a Testing setup with crack opening clip gauge; $\mathbf{b}$ notch geometry (dimensions in $\mathrm{mm}$ ) (a)

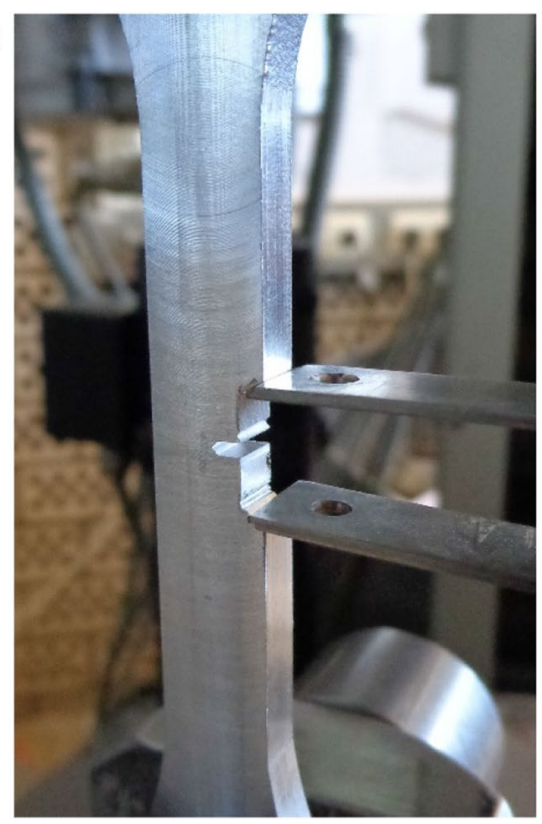

(b)

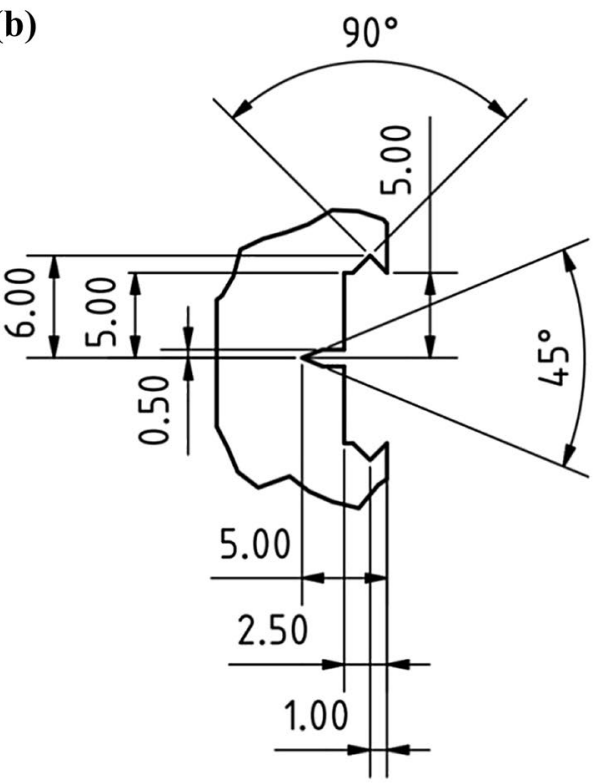

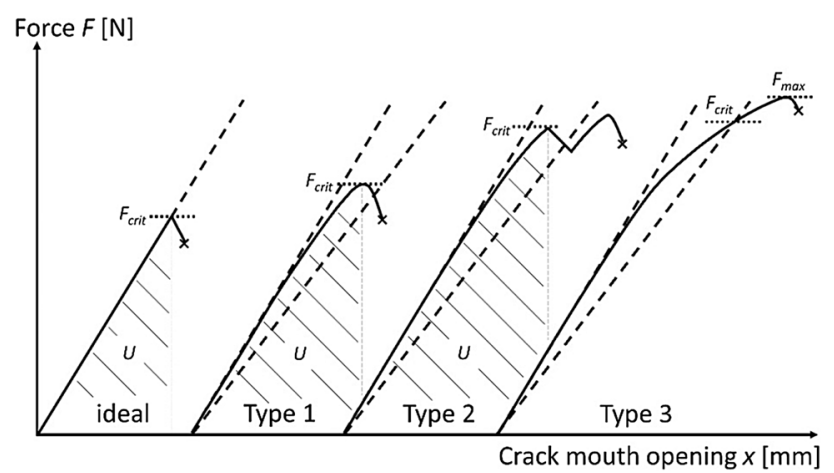

Fig. 4 Differentiation between differing crack propagation cases, according to [13]

cases (Fig. 4) to determine their type, and accordingly, the appropriate evaluation procedure. The tested samples showed the characteristics of either type 1 or type 2 behaviour (Fig. 5), with differing progressions for the secondary load peak. After the determination of the applicable cases, the following approach has been used for the subsequent evaluation of fracture toughness. The $J$ integral is calculated by the following:

$J_{\mathrm{IC}}=\frac{U}{B(W-a)} f\left(\frac{a}{W}\right)$,

with the deformation energy $U$ being the area underneath the force-crack mouth opening curve up to the first maximum and the function of the pre-crack length and specimen width being:

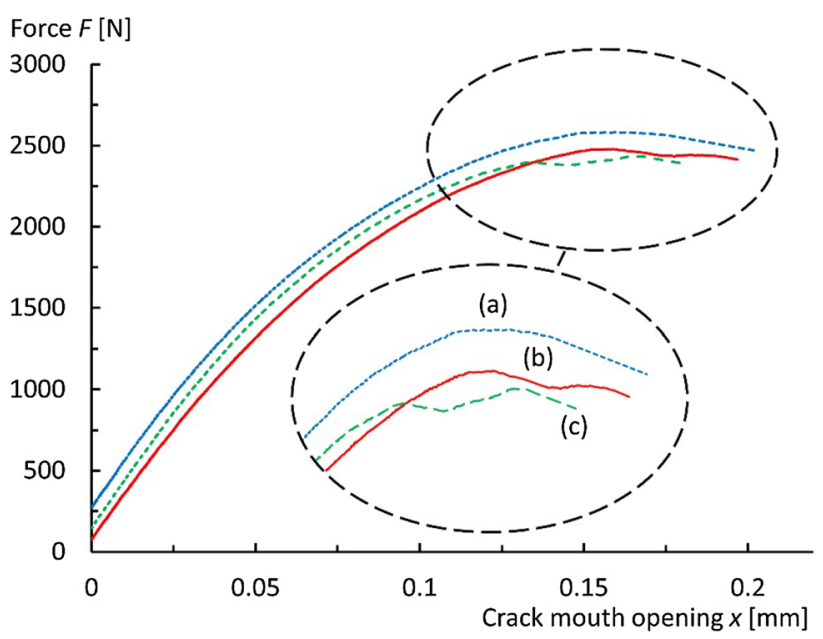

Fig. 5 Exemplary result curves: a type 1 like progression; b type 2 like progression with lower secondary peak; $\mathbf{c}$ type 2 like progression with higher secondary peak

$f\left(\frac{a}{W}\right)=2 \frac{1+\alpha}{1+\alpha^{2}}$.

The parameter $\alpha$ is calculated as:

$\alpha=\sqrt{\left(\left(\frac{2 a}{W-a}\right)+1\right)^{2}+1}-\left(\frac{2 a}{W-a}+1\right)$,

with the geometrical parameters pre-crack length $a$ and sample width $W$ being $5 \mathrm{~mm}$ and $10 \mathrm{~mm}$, respectively. As the next step, the appropriateness of the chosen configuration is checked, i.e., whether the geometrical sample dimensions and the $J$ integral result fulfil standards. To ensure validity 
of the test results, the following expression for the sample thickness $B$ ( $5 \mathrm{~mm}$ in our case) must be fulfilled:

$B>\frac{J_{\mathrm{IC}}}{\frac{1}{2}\left(R_{\mathrm{p} 0.2}+R_{\mathrm{m}}\right)}$.

If this inequality is satisfied, the $J$ integral equals the energy release rate:

$J_{\mathrm{IC}}=G_{\mathrm{IC}}$,

and finally, the fracture toughness is given by:

$K_{\mathrm{IC}}=\sqrt{\frac{G_{\mathrm{IC}} E}{\left(1-v^{2}\right)}}$.

The elastic material parameters $E, \nu$, as well as the static tensile strength values $R_{\mathrm{p} 0.2}$ and $R_{\mathrm{m}}$ were taken from the literature and were obtained from flat tensile specimens, fabricated with the identical machinery $[6,14]$. The data taken as input for the evaluation are listed in the section "Appendix". In addition, all parameters are listed and described in detail in the section "Appendix".

\subsection{Scanning electron microscopy}

High-resolution images of the fractured faces were taken with a Jeol JSM 6490 scanning electron microscope (SEMTech Solutions Inc., Massachusetts, USA).

\section{Results and discussion}

A set of four valid measurements per inclination angle has been evaluated and the results are summarised in Table 1. Due to slight differences in the tensile testing data, $K_{\text {IC }}$ values were calculated with either data set and compared side by side. Significant deviations in fracture toughness were confined to polar angles larger than $70^{\circ}$, with a varying emphasis on the decrease up to $90^{\circ}$ depending on the considered tensile data set (Fig. 6). Thus, the critical range seems to be within $\mathrm{a} \pm 10^{\circ}$ window for the crack growth direction relative to the layering. However, this conclusion is only valid for AlSi10Mg and similar AlSi alloys fabricated with PBF, inhibiting characteristic interlayer embrittlements.

Comparing the $K_{\mathrm{IC}}$ results with the known values from the early investigation of Hitzler et al. [12], whose findings are recapped in Fig. 7, the stable $K_{\mathrm{IC}}$ fracture toughness range differs, whereas the minima coincide. To explain the noted deviations, one has to consider the influence of the testing machine. While for a cross-head speed of $5 \mathrm{~mm} / \mathrm{min}$, the plateau $K_{\mathrm{IC}}$ was above $50 \mathrm{MPa} \sqrt{\mathrm{m}}$, for

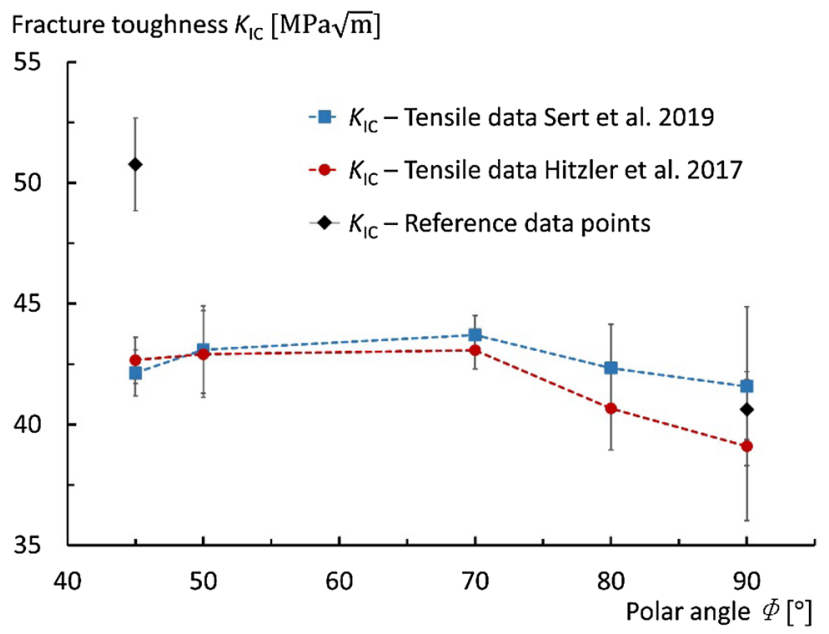

Fig. 6 Comparison of fracture toughness results; red and blue data points as obtained in this study were calculated from tensile data taken from [6, 14]; diamond-shaped black reference points stem from [12]

Table 1 Fracture toughness of notched $\mathrm{AlSi}_{10} \mathrm{Mg}$ samples as function of the polar angle $\Phi$

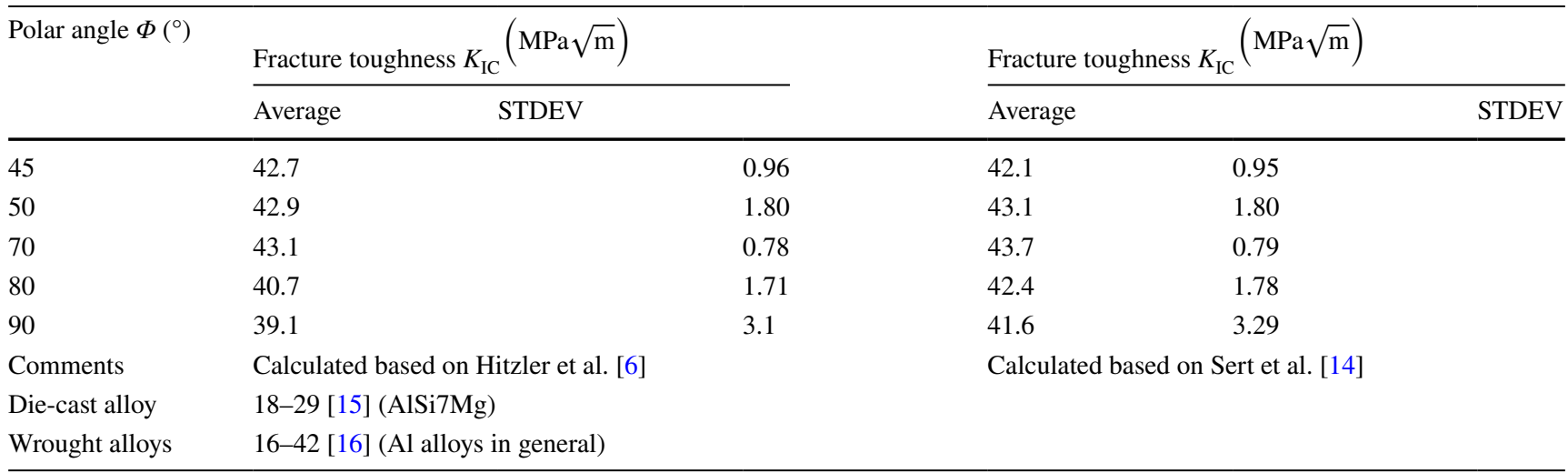

Tests were conducted at room temperature. Average values and standard deviations are listed. Furthermore, values for $K_{\mathrm{IC}}$ are listed for a die-cast alloy and wrought $\mathrm{Al}$ alloys 


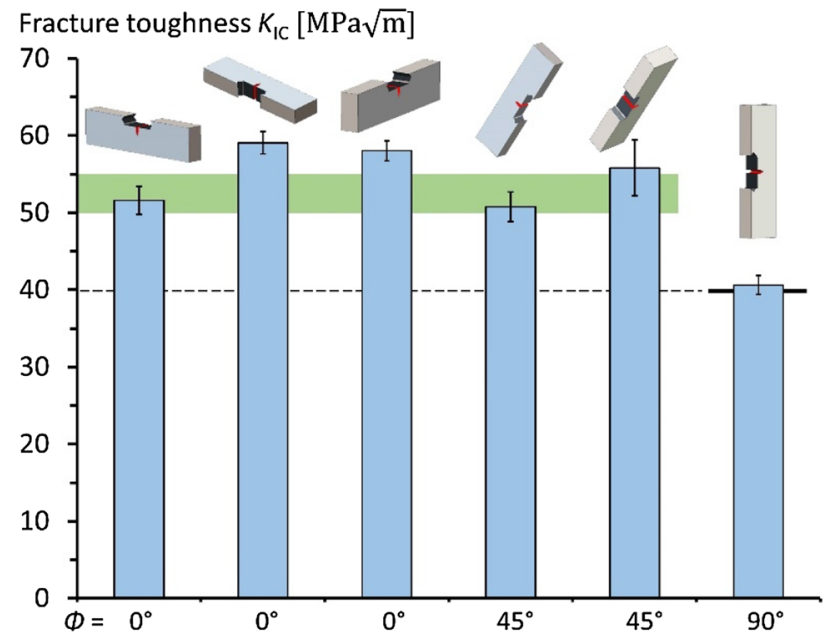

Fig. 7 Summarised fracture toughness results from Hitzler et al. [12]

Table 2 Comparison of fracture toughness studies

\begin{tabular}{llc}
\hline & This study & $\begin{array}{l}\text { Hitzler } \\
\text { et al. [12] }\end{array}$ \\
\hline Cross-head speed $(\mathrm{mm} / \mathrm{min})$ & 0.02 & 5 \\
Average maximum force $(\mathrm{kN})$ & 26 & 37 \\
Fracture toughness $K_{\mathrm{IC}}(\mathrm{MPa} \sqrt{\mathrm{m}})$ & & \\
Stable plateau & $>42$ & $>50$ \\
Minimum at $\Phi=90^{\circ}$ & 39 & 40 \\
\hline
\end{tabular}

$0.2 \mathrm{~mm} / \mathrm{min}$ was $42 \mathrm{MPa} \sqrt{\mathrm{m}}$. This indicates a marked influence of the cross-head speed on the fracture toughness, which is also the case for the average maximum force reached in the fracture toughness tests (Table 2). It should be noted that both studies, the past as well as the current study, neglected the crack initiation phase, and due to the simplifications made, the obtained results for the fracture toughness results may be higher than under ideal testing conditions.

The appearance of the fractured faces was similar amongst the specimens, independent from the polar angle. Figure $8 \mathrm{a}, \mathrm{c}$ shows the surface morphology on a $90^{\circ}$ and $45^{\circ}$ sample, respectively. Both exhibited a large amount of visible hemispherical cavities on the fractured faces. Although their shape suggests that these may be initial voids in the samples, these cannot stem from pores, since the residual porosity for the tested batch of specimens has been below $0.3 \%$. In addition, some of the cavities revealed residues of a second phase, indicating that the cavities contained precipitates (Fig. 8b). The presence of visible precipitates on the fractured face, still embedded in the $\alpha$-Al matrix, confirmed that the cavities were no initial defects in the samples (Fig. 8d, e). In short, the crack propagated along the $\mathrm{Si}$-precipitates in the $\alpha$-Al matrix, and due to the inhomogeneous distribution of Si-precipitates, these impact the preferred path for crack growth. In some instances, the early crack growth direction was not perpendicular to the applied load, and the crack propagation showed tendencies to follow the layering in the samples (Fig. 8f). This, however, is only the case during the early crack growth, and with the constantly decreasing cross-sections, the crack eventually takes the path perpendicular to the applied load until complete rupture of the sample.

\section{Conclusion}

Notched tensile samples built in the polar angle range of $45^{\circ}-90^{\circ}$ were subject to mode I fracture toughness testing to answer the question of the critical proximity of the crack growth direction and the orientation of the weakened interlayer connection. The end of the $K_{\mathrm{IC}}$ plateau was pinpointed in the range of a $10^{\circ}-20^{\circ}$ proximity, with the $20^{\circ}$ offset representing the last recorded stable $K_{\mathrm{IC}}$ value, followed by a steady decline to the worst-case scenario, i.e., crack propagation between consecutive layers ( $0^{\circ}$ offset). The fracture toughness proofed itself to be sensitive to the testing speed. For a testing speed of $0.2 \mathrm{~mm} / \mathrm{min}$, the $K_{\text {IC }}$ plateau was determined around $42 \mathrm{MPa} \sqrt{\mathrm{m}}$ with an approximated $10 \%$ reduction in fracture toughness for the worst-case scenario. For comparison, a $20 \%$ reduction was noted for a testing speed of $5 \mathrm{~mm} / \mathrm{s}$, which also raised the $K_{\mathrm{IC}}$ plateau to above $50 \mathrm{MPa} \sqrt{\mathrm{m}}$.

With the critical range of crack growth directions relative to the layering being identified, the next step will be the examination of standardised CT specimens, including the pre-cycling for crack initiation, to quantify the error made by our simplifications and to provide solid characteristic values for both the stable plateau and the worst-case scenario.

Acknowledgements Open Access funding provided by Projekt DEAL. Sincere appreciation to Michael Sedlmajer and Rene Klink for their kind support and effort in the sample fabrication and preparation.

\section{Compliance with ethical standards}

Conflict of interest The authors declare that there is no conflict of interest.

Open Access This article is licensed under a Creative Commons Attribution 4.0 International License, which permits use, sharing, adaptation, distribution and reproduction in any medium or format, as long as you give appropriate credit to the original author(s) and the source, provide a link to the Creative Commons licence, and indicate if changes were made. The images or other third party material in this article are included in the article's Creative Commons licence, unless indicated otherwise in a credit line to the material. If material is not included in 

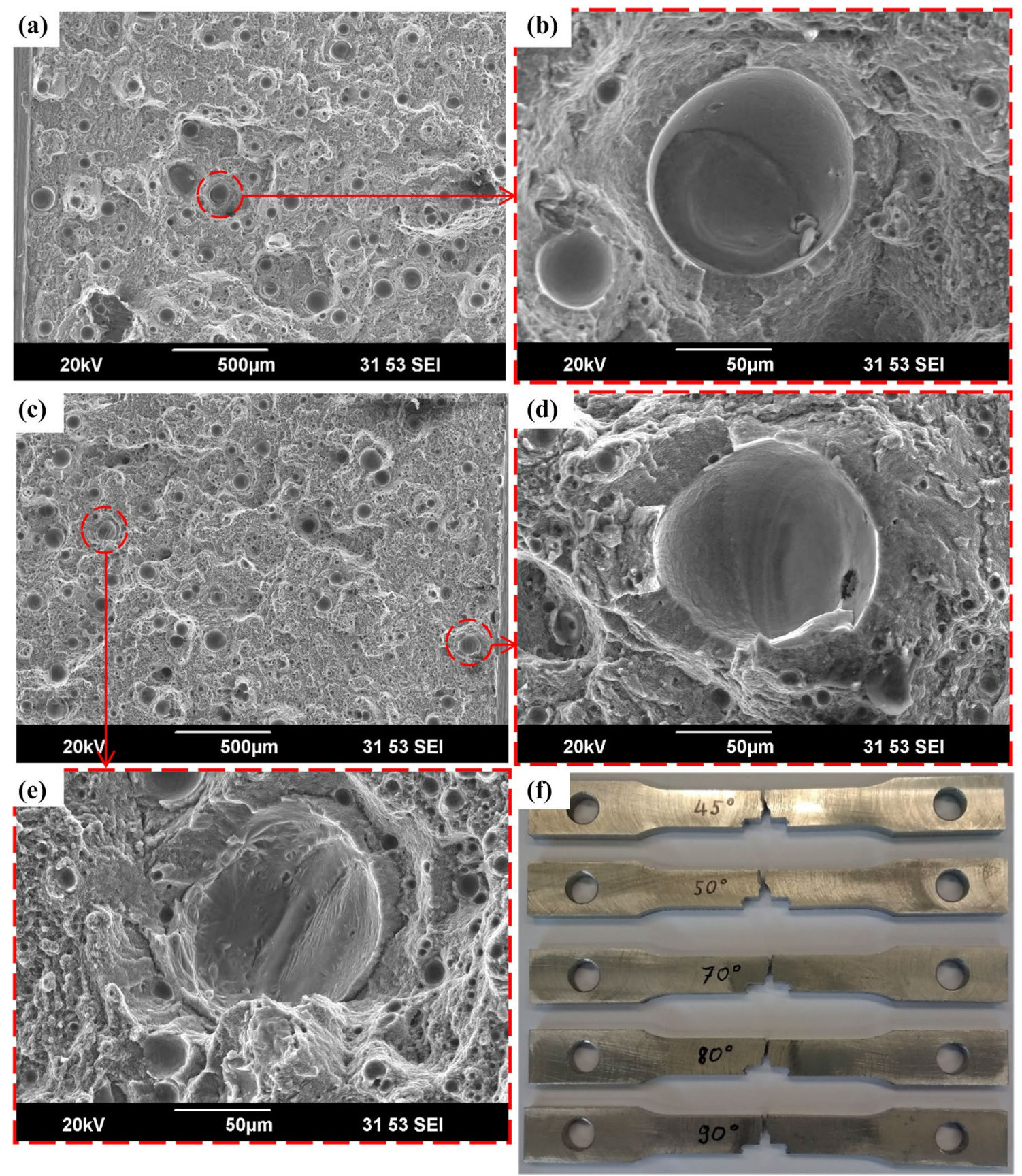

Fig. 8 Scanning electron microscope images of fractured faces: Depicted are a a $90^{\circ}$ sample, a c $45^{\circ}$ sample and magnifications b, d and exemplifying present Si-precipitates in the fractured faces and

the article's Creative Commons licence and your intended use is not permitted by statutory regulation or exceeds the permitted use, you will need to obtain permission directly from the copyright holder. To view a copy of this licence, visit http://creativecommons.org/licenses/by/4.0/. cavities, containing fractions of the previously embedded Si-precipitate. f Instance of early crack propagation paths seemingly coinciding with the layering in samples

\section{Appendix}

The section "Appendix" contains further details and data to supplement the given information and evaluation in the main section and to allow for repetition and thorough comparisons. In Table 3, the nomenclature employed throughout the entire work is described and abbreviations are explained. 
Table 3 Nomenclature in accordance to ASTM E 399-08 and DIN EN ISO 6892-1:2009-12

\begin{tabular}{|c|c|c|c|}
\hline Parameter & Abbrev. & Explanation & Unit \\
\hline Pre-crack length & $a$ & Depth of the initial notch, per definition $0.45 \times W<a<0.55 \times W$ & $(\mathrm{~mm})$ \\
\hline Elongation at failure & $A_{\mathrm{t}}$ & Total elongation (elastic and plastic) at failure & $(\%)$ \\
\hline Thickness & $B$ & Thickness of the specimen & $(\mathrm{mm})$ \\
\hline Young's modulus & $E$ & Material stiffness & $(\mathrm{MPa})$ \\
\hline Force & $F$ & Applied load, measured by the load cell & $(\mathrm{N})$ \\
\hline Critical force & $F_{\text {crit }}$ & $\begin{array}{l}\text { Critical load, being either the maximum force or the force for crack } \\
\text { propagation }\end{array}$ & $(\mathrm{N})$ \\
\hline Energy release rate & $G_{\text {IC }}$ & Verified deformation energy in relation to the crack front length & $\left(\frac{N}{m}\right)$ \\
\hline$J$ integral & $J_{\text {IC }}$ & Deformation energy in relation to the crack front length & $\left(\frac{N}{m}\right)$ \\
\hline Fracture toughness & $K_{\mathrm{IC}}$ & Critical stress intensity factor (mode 1 ) & $(\mathrm{MPa} \sqrt{\mathrm{m}})$ \\
\hline Notch-width ratio & $N$ & Per definition $N<W / 10$ & $(\mathrm{~mm})$ \\
\hline Crack front length & $r$ & Crack propagation perpendicular to load & $(\mathrm{mm})$ \\
\hline Yield stress & $R_{\mathrm{p} 0.2}$ & Stress at $0.2 \%$ plastic deformation, also known as $\sigma_{\mathrm{F}}$ & $(\mathrm{MPa})$ \\
\hline Ultimate tensile strength (UTS) & $R_{\mathrm{m}}$ & Material parameter, maximum stress & $(\mathrm{MPa})$ \\
\hline Deformation energy & $U$ & Required energy for crack propagation & $(\mathrm{Nm})$ \\
\hline Width & $W$ & Width of the specimen & $(\mathrm{mm})$ \\
\hline Crack mouth opening & $x$ & Displacement at the root of the notch & $(\mathrm{mm})$ \\
\hline Correction factor & $\alpha$ & Correction factor for CT-specimen & - \\
\hline Poisson's ratio & $\nu$ & Contraction number of the material in the elastic range & - \\
\hline
\end{tabular}

Table 4 Parameter sets utilized for fabrication of $\mathrm{AlSi}_{10} \mathrm{Mg}$ powder on an SLM 280HL machine

\begin{tabular}{llllll}
\hline & $\begin{array}{l}\text { Scan } \\
\text { speed } \\
(\mathrm{mm} / \mathrm{s})\end{array}$ & $\begin{array}{l}\text { Laser } \\
\text { power } \\
(\mathrm{W})\end{array}$ & $\begin{array}{l}\text { Hatch } \\
\text { distance } \\
(\mathrm{mm})\end{array}$ & $\begin{array}{l}\text { Scan vec- } \\
\text { tor length } \\
(\mathrm{mm})\end{array}$ & $\begin{array}{l}\text { Rotation } \\
\text { angle } \\
\text { increment } \\
\left({ }^{\circ}\right)\end{array}$ \\
\hline Contour & 600 & 350 & - & - & - \\
Core & 930 & 350 & 0.17 & 10 & 90 \\
Support & 900 & 350 & - & - & - \\
\hline
\end{tabular}

The parameter sets for the fabrication of the samples are summarized in Table 4 and have been found to result in an averaged relative density of $99.5 \%$ based on the Archimedes method and an area porosity of $0.3 \%$ determined on microsections [17].

The material parameters listed in Table 5 were examined in destructive tensile tests on flat tensile specimens (German standard DIN 50125-E $5 \times 10 \times 40$ ) and stem from two independent studies [6, 14]. In both studies, tensile tests were carried out in accordance to the DIN EN ISO 6892-1 standard with a cross-head speed of $5 \mathrm{~mm} / \mathrm{s}$ at room temperature. Samples tested in Hitzler et al. [6] were fabricated with the identical parameter sets than the samples investigated in the current study (Table 4) and tested in their non-heat-treated, but machined condition. Poisson's ratio was determined via readings of attached strain gauges. In the study of Sert et al. [14], samples were
Table 5 Summary of literature values from uniaxial tensile tests: values in brackets indicate interpolated values or near neighbor values

\begin{tabular}{lccccccr}
\hline $\begin{array}{l}\text { Polar angle } \\
\Phi\left(^{\circ}\right)\end{array}$ & \multicolumn{2}{l}{$\begin{array}{l}\text { Young's modulus } E \\
(\mathrm{GPa})\end{array}$} & Poisson's ratio $\nu(-)$ & $\begin{array}{l}\text { Yield strength } R_{\mathrm{p} 0.2} \\
(\mathrm{MPa})\end{array}$ & \multicolumn{2}{l}{$\begin{array}{l}\text { Ultimate tensile } \\
\text { strength } R_{\mathrm{m}} \\
(\mathrm{MPa})\end{array}$} \\
\hline \multicolumn{2}{l}{ Hitzler et al. } \\
45
\end{tabular}

Data of both bold and italics is necessary to explain calculated results in the main part of the manuscript 
tested with their as-fabricated surface condition, however, after a post artificial ageing treatment at $170{ }^{\circ} \mathrm{C}$ for $4 \mathrm{~h}$. The heat treatment was performed to overcome the inhomogeneity in the precipitation hardening states across the built height, caused by differing dwell times at elevated temperatures in the build chamber [18]. Moreover, the irradiation parameters for the core differed slightly, in particular the scan speed was set to $1150 \mathrm{~mm} / \mathrm{s}$ (opposed to $930 \mathrm{~mm} / \mathrm{s}$ ). Poisson's ratio was determined via a secondary extensometer, measuring the strain perpendicular to the primary extensometer.

\section{References}

1. Hitzler L, Merkel M, Hall W, Öchsner A (2018) A review of metal fabricated with laser- and powder-bed based additive manufacturing techniques: process, nomenclature, materials, achievable properties, and its utilization in the medical sector. Adv Eng Mater 20:1700658

2. DebRoy T, Wei HL, Zuback JS, Mukherjee T, Elmer JW, Milewski JO, Beese AM, Wilson-Heid A, De A, Zhang W (2018) Additive manufacturing of metallic components-process, structure and properties. Prog Mater Sci 92:112-224

3. Zhang D, Sun S, Qiu D, Gibson MA, Dargusch MS, Brandt M, Qian M, Easton M (2018) Metal alloys for fusion-based additive manufacturing. Adv Eng Mater 20:1700952

4. Hitzler L, Hirsch J, Heine B, Merkel M, Hall W, Öchsner A (2017) On the anisotropic mechanical properties of selective laser melted stainless steel. Materials 10:1136

5. Hitzler L, Hirsch J, Tomas J, Merkel M, Hall W, Öchsner A (2019) In-plane anisotropy of selective laser melted stainless steel: the importance of the rotation angle increment and the limitation window. Proc Inst Mech Eng Part L J Mater Des Appl 233:1419-1428

6. Hitzler L, Janousch C, Schanz J, Merkel M, Heine B, Mack F, Hall W, Öchsner A (2017) Direction and location dependency of selective laser melted AlSi10Mg specimens. J Mater Process Technol 243:48-61
7. Buchbinder D, Meiners W, Wissenbach K, Poprawe R (2015) Selective laser melting of aluminum die-cast alloy-correlations between process parameters, solidification conditions, and resulting mechanical properties. J Laser Appl 27:S29205

8. Prashanth KG, Scudino S, Klauss HJ, Surreddi KB, Löber L, Wang Z, Chaubey AK, Kühn U, Eckert J (2014) Microstructure and mechanical properties of Al-12Si produced by selective laser melting: effect of heat treatment. Mater Sci Eng A 590:153-160

9. Aboulkhair NT, Tuck C, Ashcroft I, Maskery I, Everitt NM (2015) On the precipitation hardening of selective laser melted AlSi10Mg. Metall Mater Trans A 46:3337-3341

10. Tang M, Pistorius PC (2017) Anisotropic mechanical behavior of AlSi10Mg parts produced by selective laser melting. JOM 69:516-522

11. Aboulkhair NT, Simonelli M, Parry L, Ashcroft I, Tuck C, Hague $R$ (2019) 3D printing of aluminium alloys: additive manufacturing of aluminium alloys using selective laser melting. Prog Mater Sci 106:100578

12. Hitzler L, Hirsch J, Schanz J, Heine B, Merkel M, Hall W, Öchsner A (2019) Fracture toughness of selective laser melted AlSi10Mg. Proc Inst Mech Eng Part L J Mat Des Appl 233:615-621

13. Heine B (2011) Werkstoffprüfung-Ermittlung von Werkstoffeigenschaften, 2nd edn. Carl Hanser Verlag, Leipzig

14. Sert E, Schuch E, Hitzler L, Werner E, Öchsner A, Merkel M (2019) Tensile strength performance with determination of Poisson's ratio of additively manufactured AlSi10Mg samples. Matwiss u Werkstofftech 50:539-545

15. Srinivasan M, Seetharaman S (2012) Fracture toughness of metal castings. In: Srinivasan M (ed) Science and technology of casting processes. Intech Open Science, Rijeka

16. Richard HA (1990) Grundlagen und Anwendungen der Bruchmechanik. Technische Mechanik 11(2):69-80

17. Hitzler L, Janousch C, Schanz J, Merkel M, Mack F, Öchsner A (2016) Non-destructive evaluation of AlSi10Mg prismatic samples generated by selective laser melting: influence of manufacturing conditions. Mat-wiss u Werkstofftech 47:564-581

18. Sert E, Hitzler L, Heine B, Merkel M, Werner E, Öchsner A (2019) Influence of heat treatments on the microstructure and hardness of additive manufactured AlSi10Mg samples. Pract Metallogr 56:91-105 